\title{
A SOCIALIZAÇÃO DA MEDICINA NO INTERIOR Paulista: o Caso de São Carlos-SP (1889-1988) ${ }^{1}$
}

\author{
Fabio de Oliveira ALMEIDA*
}

\begin{abstract}
RESUMO: O artigo focaliza, entre 1889-1988, a interiorização da medicina socializada e o desenvolvimento econômico e político do interior paulista. Considera, em especial, o impacto da centralização política do Estado sobre o desenvolvimento brasileiro, a consequente ampliação da medicina estatal e seus efeitos sobre a autonomia profissional médica. A análise verifica o particular caso de socialização da medicina em São Carlos-SP, onde aqueles fatores sociais mostraram-se influentes no período, conferindo especificidades sobre a autonomia médica. Do ponto de vista desta autonomia, a socialização produziu efeitos positivos e negativos. A realidade são-carlense expressa um caso representativo de como se deu a socialização da medicina no interior paulista. A pesquisa investigou fontes bibliográficas, Atas da Sociedade Médica de São Carlos e o resultado de 15 entrevistas baseadas em história oral com médicos e cidadãos são-carlenses.
\end{abstract}

PALAVRAS-CHAVE: Interiorização. Socialização da medicina. Desenvolvimento. Autonomia profissional da medicina. São Carlos-SP.

\section{Introdução}

A sociologia das profissões ganhou força no Brasil entre as décadas de 1980 e 1990, assumindo maior influência nos anos 2000 com pesquisas que abordam a realidade dos grupos profissionais, seja no espaço do mercado, seja em sua relação com o Estado e as políticas públicas (BONELLI; DONATONI, 1996, BONELLI,

\footnotetext{
UFSCar - Universidade Federal de São Carlos. Programa de Pós-Graduação em Sociologia. São Carlos - SP -Brasil. 13565-905 - fabioliveiral@yahoo.com.br. https://orcid.org/0000-0002-9378-3272.

1 Esta pesquisa foi desenvolvida com bolsas FAPESP e CAPES.
} 
1999, BONELLI; NUNES; MICK, 2017). As profissões têm mantido elos com outros grupos sociais e participado de vários processos intervenientes nas relações entre sociedade e Estado (BARBOSA, 1993; BONELLI, 2002). Nesse contexto, o processo de socialização da medicina representa a forma como segmentos médicos brasileiros compreenderam, historicamente, o movimento de expansão de serviços estatais de saúde pública e assistência médica, o que mobilizou a medicina durante o século XX (ALMEIDA, 2013).

No caso brasileiro, a socialização da medicina e sua interiorização em diferentes regiões - tal como para o município de São Carlos-SP - foi condicionada pela interiorização do desenvolvimento socioeconômico e político (KERBAUY, 2000) que foi favorecido pela ação do Estado nacional e sua centralização política, o que tornou este fator-chave, tanto do desenvolvimento (BENEVIDES, 1979; DRAIBE, 1985) como, por decorrência, da extensão de serviços estatais de saúde a diferentes localidades (ALMEIDA, 2016). Tais mudanças contaram com a participação de grupos profissionais de nível superior, os quais, por isso, avançaram com seus processos de profissionalização, ao mesmo tempo em que foram afetados por alterações nos padrões de desigualdade e de estratificação ocupacional, o que atingiu em especial as classes médias (BARBOSA,1998).

Entre 1889 e 1930, o desenvolvimento brasileiro vinculou-se à força da economia agroexportadora (e, em particular, à produção cafeeira paulista) e ao contexto de descentralização política do Estado - que atingiu a área estatal de saúde. Desde a Era Vargas (1930-1945), até pelo menos até o final da década de 1980, o desenvolvimento econômico e político do país baseou-se no avanço urbano-industrial, sendo que a centralização política do Estado - que na área de saúde pública já havia percebido avanços mesmo antes de 1930 (HOCHMAN, 1998) - teve papel de grande relevo, o que conferiu ao governo federal um papel estratégico não apenas sobre mudanças econômicas e políticas, mas em relação à própria expansão de órgãos e serviços de saúde pública e assistência médica estatal, os quais vieram a ser direcionados ao impulso urbano-industrial do país, favorecendo a expansão de serviços voltados, de modo concentrado, ao apoio de setores sociais considerados fundamentais à industrialização e à urbanização (DONNANGELO, 1975).

A expansão e centralização política dos serviços estatais de saúde pública e assistência médica afetaram diferentes regiões, as quais foram atingidas pela ação de novos órgãos públicos de saúde, que foram sendo criados ou expandidos em um processo de interiorização da medicina estatal. Esse processo atingiu serviços sanitários e secretarias de saúde estaduais, órgãos do Ministério da Saúde e instâncias governamentais de assistência médica previdenciária (institutos previdenciários estaduais e órgãos federais, tais como, as Caixas e Institutos de Aposentadoria e Pensões (CAP's/IAP's), o Serviço de Assistência Médica Domiciliar e de Urgência 
(SAMDU), o Instituto Nacional da Previdência Social (INPS), o Instituto Nacional de Assistência Médica da Previdência Social (INAMPS) e o Fundo de Assistência ao Trabalhador Rural (FUNRURAL). Contudo, embora se pudesse observar esse movimento em escala nacional, deve-se reconhecer que o mesmo assumiu características particulares segundo especificidades regionais e locais de cada municipalidade, com desdobramentos ao profissionalismo médico e à sua autonomia profissional (FREIDSON, 2009).

Tal autonomia seria relativa a possíveis ingerências consideradas danosas pelos profissionais à condição de seus grupos, as quais poderiam ser exercidas pelos patrões (de organizações públicas ou privadas), pela clientela ou pelos demais grupos sociais, econômicos e políticos com os quais as categorias profissionais se relacionam no mundo do trabalho, de tal forma que o estabelecimento e a manutenção de tais condições eventualmente levam a mobilização de grupos profissionais em direção à defesa de valores sociais considerados superiores, os quais poderiam ser atingidos através do trabalho, produtos e serviços oferecidos pelos profissionais, e que, segundo estes advogam, poderiam ser mais bem promovidos a partir da preservação, seja da autonomia profissional, seja da neutralidade da expertise.

Com efeito, autonomia profissional é observada aqui em sua dupla dimensão social, ou seja: “(...) autonomia da influência ou poder de outros, e autonomia para influenciar ou exercer poder sobre outros" (FREIDSON, 2009, p. 410), de tal forma que, nestes termos, o profissionalismo representa uma lógica de organização da divisão do trabalho, a partir da qual o poder dos grupos profissionais, em seu relacionamento com outros setores e instituições sociais, estabelece-se, tanto na sociedade mais ampla como no sistema ocupacional em particular, por meio, acima de tudo, das vantagens - autonomia técnica e controle sobre o próprio trabalho que são oferecidas pelo monopólio de determinada expertise e por credenciais, que implicam os mais fundamentais recursos de poder dos grupos profissionais (FREIDSON, 1996).

Nestas condições, a autonomia técnica e o controle sobre o próprio trabalho baseados na neutralidade, domínio e monopólio de determinada expertise - criam um âmbito de atividades onde o profissional (e não a hierarquia organizada de trabalho, pública ou privada) - pode se tornar o ator social central da realidade onde o mesmo atua. Embora não seja a única fonte de poder profissional, a articulação entre tais mecanismos sociais interfere no balanço de poder tanto dentro das profissões como entre estas e os demais setores e instituições do sistema ocupacional, bem como com a sociedade e o poder de Estado. A autonomia, baseada na neutralidade da expertise, confere às profissões relativa liberdade para que realizem suas atividades ocupacionais com independência técnica. 
Mas além da autonomia técnica em si, também existiriam outras extensões consideradas sociologicamente importantes da autonomia profissional como um conceito multidimensional, as quais poderiam favorecer ou não a condição de inserção de determinada profissão na sociedade, bem como impulsionar ou não o âmbito em que a autonomia técnica é estabelecida, conferindo particularidades à dinâmica do profissionalismo. Tais dimensões matizam diferentes liames sociais que, ao lado do aspecto estritamente técnico, igualmente afetam a autonomia dos grupos profissionais, conectando-os, relativamente, aos demais grupos, instituições e processos sociais que atingem a realidade onde as profissões atuam. Tais dimensões da autonomia profissional seriam a autonomia econômica e a autonomia política dos grupos profissionais (FREIDSON, 2009).

Desde a sua dimensão econômica, a autonomia profissional diz respeito às formas de organização social da prática profissional e ao nível de liberdade que uma profissão possui em relação a isso, observados do ponto de vista das modalidades de distribuição de benefícios econômicos aos seus praticantes, o que pode gerar implicações sociais, econômicas e políticas internas e externas a uma profissão, afetando a conformação do profissionalismo. Visto que a organização social da profissão tanto em termos técnicos como do ponto de vista econômico depende de negociações com outros grupos ocupacionais ou profissionais e com a sociedade em geral, e como implica variações nas relações de poder internas às profissões e entre estas e o meio social de seu entorno, há um sentido político ligado à prática profissional, sendo fundamentais as maneiras como as profissões se relacionam com o Estado e a política.

O conjunto das relações variáveis entre as três dimensões da autonomia profissional e seus desdobramentos para a realidade do profissionalismo sugere o envolvimento e a mútua influência sociológica (WEBER, 1983) entre grupos profissionais e outros grupos e instituições sociais, bem como em relação a demais processos históricos que permeiam a realidade social onde se inserem os grupos profissionais. O conceito de autonomia profissional é relacionado aqui ao que Freidson e outros tratam como a influência das relações de poder junto a dinâmica profissional (RODRIGUES, 2001). Este foco ganhou força com a ascensão de abordagens weberianas ou neoweberianas (seguidas de outros tipos de perspectivas), que desde os anos 1970 e 1980 passaram a renovar o debate em sociologia das profissões, vindo a influenciar pesquisas sobre a realidade brasileira (BARBOSA, 1993; SANTOS, 2011).

Neste trabalho, são considerados os fatores e processos sociais condicionantes que afetam as relações de poder que permeiam a interiorização da medicina socializada, assim como seu impacto sobre a autonomia profissional e o profissionalismo da categoria médica são-carlense, considerando-se, para isso, as conexões entre a interiorização do profissionalismo médico e o processo de interiorização do desen- 
volvimento (KERBAUY, 2000), o que é observado focalizando-se o papel da centralização política do Estado brasileiro e a interiorização de suas estruturas burocráticas na área de saúde do município de São Carlos-SP. Dessa forma, este município foi escolhido como um caso a ser analisado, pois, em sua trajetória histórica, conviveu com avanços em seu desenvolvimento urbano-industrial e a influência da centralização do Estado brasileiro (TRUZZI, 2007; LIMA, 2008) - fatores responsáveis por mudanças no poder local, em sua área de saúde e na inserção de grupos médicos.

A pesquisa inicia-se com a criação da República (1889), já que o município em questão é criado em 1880, mas concentra a análise entre 1930-1988, quando o processo de centralização do Estado ganha dinamismo, afetando a socialização da medicina local. São Carlos-SP expressa um caso representativo de socialização da medicina no interior paulista. Analisa dados bibliográficos sobre aspectos sociológicos pertinentes, Atas da Sociedade Médica de São Carlos (principal entidade médica local no período) e os resultados de 15 entrevistas baseadas em história oral (MEIHY; RIBEIRO, 2011) - realizadas com médicos e moradores de São Carlos-SP, os quais trabalham ou habitam o município. Estes tiveram seus nomes trocados por expressões, tais como, Médico ou Morador(a), sendo incorporados ao texto com uma indicação numérica em ordem crescente, conforme apareceram na análise - além de informações gerais que não comprometem o anonimato.

\section{A medicina socializada em São Carlos-SP}

O município de São Carlos-SP experimentou a interiorização da medicina socializada conforme especificidades de sua dinâmica de poder e segundo suas conexões com os poderes políticos estadual e nacional, produzindo distintos efeitos sobre a autonomia profissional médica (FREIDSON, 2009).

Ainda na Primeira República (1889-1930), o processo de socialização da medicina que atinge São Carlos-SP associou-se ao movimento de desenvolvimento da medicina estatal do país desse período - então organizada de modo descentralizado, principalmente por estruturas sanitárias estaduais, por vezes apoiadas pelo governo federal (CASTRO SANTOS, 2004) -, de tal forma que, em São Carlos-SP, pode-se verificar a existência de apenas alguns serviços de saúde pública estabelecidos por iniciativa do governo paulista. Estes se desdobravam nas atividades das Delegacias Regionais de Hygiene ou Saúde e de seus delegados, que cuidavam das questões de saúde pública da localidade e de sua região de abrangência.

Desde o seu maior impulso sobre a localidade, nos anos 1930-1940 e em meio a Era Vargas, a socialização da medicina que atinge o interior paulista e o município de São Carlos-SP agora não mais se restringiu ao setor de saúde pública ou às iniciativas do governo estadual, expandindo-se para as ações de assistência 
médica previdenciária, as quais foram cada vez mais impulsionadas pelo governo federal - o que causou temores entre colegas são-carlenses e de outras regiões paulistas a respeito do consequente assalariamento de médicos e da possibilidade de concorrência entre os serviços estatais e o trabalho que os demais colegas realizavam na clínica liberal (ALMEIDA, 2011).

Logo após a sua criação, ainda em 1948, a Sociedade Médica de São Carlos (SMSC), assim como outras associações locais do interior paulista e da própria organização estadual da Associação Paulista de Medicina (APM), além da Sociedade de Medicina e Cirurgia de São Paulo (SMCSP), dadas as preocupações que sentiam diante das mudanças emergentes com tal processo de socialização, mobilizaramse a fim de reivindicar melhores condições de trabalho para os profissionais que atuavam nos serviços sanitários paulistas, resultando na luta pela equiparação de vencimentos junto aos advogados do Departamento Jurídico do Estado de São Paulo. Esta luta desenvolveu-se através do Movimento de Assembleia Permanente de Médicos e Engenheiros, quando ambas as categorias aliaram-se em benefício desta reivindicação que afetaria os dois grupos.

Em meio a tal mobilização, houve manifestações de lideranças médicas paulistas sobre o processo de socialização em curso no país e como a categoria médica poderia reagir a ele (ALMEIDA, 2011, 2014). Mesmo divergindo de certas estratégias de ação, os médicos de São Carlos-SP acabaram participando de todas as tomadas de posição do Movimento de Assembleia Permanente. Tais questões foram intensamente debatidas no âmbito da SMSC e por colegas de outras localidades do estado.

Com o intuito de produzir um posicionamento mais claro sobre o assunto e oferecê-lo à organização central do Movimento de Assembleia Permanente e à direção da Associação Paulista de Medicina (APM), à qual a SMSC havia se filiado, em reunião de agosto de 1950, os sócios da SMSC estabeleceram que, no que concerne ao tema, colocavam-se em posição favorável, mas com reservas à ampliação dos serviços socializados - que poderia seguir seu curso, desde que se restringisse ao oferecimento de serviços àqueles que não fossem capazes de arcar com os custos dos atendimentos médicos de que necessitassem, e se, além disso, os serviços socializados fossem organizados ou somente pelo Estado ou também pelos órgãos assistenciais da indústria e do comércio. Os médicos são-carlenses reconheciam vantagens para a população pobre através do processo de socialização, desde que a categoria médica não fosse obrigada a prestar serviços gratuitos nem se submeter à exploração de clientes abastados, os quais talvez viessem, indevidamente, a procurar pelos atendimentos socializados (SOCIEDADE MÉDICA DE SÃO CARLOS, 09 de agosto de 1950. Livro Ata 01, p. 24-25).

Assim como colegas de profissão em outras localidades paulista, os médicos de São Carlos-SP logo perceberam que a temida concorrência dos serviços 
socializados em relação à clínica privada liberal não iria se materializar, podendo os dois tipos de trabalho cooperar (Entrevista com o Médico 01, profissional de São Carlos-SP, entre 80-85 anos de idade). De sua parte, os médicos atuantes nos serviços sanitários, em determinadas situações, buscavam auxílio e cooperação profissional com os demais colegas que atuavam na assistência médica, inclusive na prática liberal, bem como em relação às atividades da SMSC (SOCIEDADE MÉDICA DE SÃO CARLOS. Ata da 92a reunião ordinária, de 02 de maio de 1956. Livro Ata 01, p. 23-25). Os contatos entre médicos, órgãos sanitários e a SMSC eram facilitados, visto os delegados de saúde sempre se tornarem sócios da entidade médica local (SOCIEDADE MÉDICA DE SÃO CARLOS. Ata da $103^{\mathrm{a}}$ reunião ordinária, de 03 de abril de 1957. Livro Ata 01, p. 45-46; SOCIEDADE MÉDICA DE SÃO CARLOS. Ata da $106^{a}$ reunião ordinária, de 05 de agosto de 1957 . Livro Ata 01, p. 50-51).

A socialização realizada nos serviços sanitários paulistas implicou também outras situações em que o poder, o interesse e a autonomia profissionais dos médicos de São Carlos-SP foram relativamente contrariadas em razão da influência de decisões tomadas pela hierarquia político-administrativa da secretaria estadual de saúde, resultando, frequentemente, em reações do grupo médico local e de sua associação representativa, já que se reconheciam afetados na dimensão política de sua autonomia profissional. Quanto a isso, em 1950, os colegas, no âmbito da $\mathrm{SMSC}$, receberam um informe que os deixaram alarmados. Este fato se tratava de determinada dispensa de um dos sócios da entidade - no caso, o doutor Serafim Justo - que vinha sendo o médico do Subposto de Saúde em Santa Eudóxia (Distrito de São Carlos-SP). Diante disso, foi criada uma comissão especial de três membros da entidade para que se conseguissem maiores esclarecimentos e para ouvir o próprio doutor Justo ${ }^{2}$. Outro fato semelhante referiu-se ao que se discutiu em reunião da entidade em fevereiro de 1965, quando da substituição do então delegado regional de saúde - o qual, contrariado, veio a deixar o cargo por decisão da administração estadual. Embora demonstrando ter-se ressentido com a apatia dos colegas da SMSC, estes justificaram que não ficaram indiferentes, encaminhando ofícios sobre o assunto (SOCIEDADE MÉDICA DE SÃO CARLOS. Ata da $196^{\mathrm{a}}$ reunião ordinária, de 03 de fevereiro de 1965. Livro Ata 03, p. 96-97).

Essas situações evidenciaram a nova realidade da profissão médica local diante da expansão dos serviços públicos de saúde, pois os médicos pouco poderiam fazer para contornar as situações discutidas, na medida em que a esfera de decisão sobre tais assuntos ficava legalmente sob a jurisdição da secretaria de saúde estadual, algo em parte sentido também em relação à assistência médica previdenciária, tanto

\footnotetext{
2 A esse respeito: SOCIEDADE MÉDICA DE SÃO CARLOS. Ata da $27^{\mathrm{a}}$ reunião ordinária, de 06 de dezembro de 1950, p. 29.
} 
estadual como federal, o que afetava a autonomia profissional dos médicos de São Carlos-SP, seja do ponto de vista técnico, socioeconômico ou político.

Nesse sentido, sobre o Instituto de Aposentadoria e Pensões dos Estivadores e Transportes de Cargas (IAPETEC), por exemplo, bem como em relação ao Instituto de Assistência Médica do Estado de São Paulo (IAMSP), a SMSC viuse diante de uma situação que contrariava os interesses da categoria, já que tais serviços previdenciários estavam preferindo encaminhar seus pacientes para atendimentos no município vizinho de Araraquara-SP, em detrimento dos colegas são-carlenses (SOCIEDADE MÉDICA DE SÃO CARLOS. Ata da $208^{\mathrm{a}}$ reunião ordinária, de 06 de abril de 1966. Livro Ata 03, p. 115-116). Em outro contexto, relativo aos serviços do Instituto de Aposentadoria e Pensões dos Industriários (IAPI), pacientes e profissionais chegaram a sofrer demoras nas autorizações de cirurgias em 1966, o que trouxe contratempos técnicos e econômicos ao trabalho médico local (SOCIEDADE MÉDICA DE SÃO CARLOS. Ata da $208^{\mathrm{a}}$ reunião ordinária, de 06 de abril de 1966. Livro Ata 03, p. 115-116). Ademais, os médicos da SMSC também se sentiram contrariados quando os institutos previdenciários locais resolveram incluir o serviço de assistência obstétrica do Instituto de Aposentadoria e Pensões dos Comerciários (IAPC) e do IAPTEC no contrato em vigor com o IAPI (SOCIEDADE MÉDICA DE SÃO CARLOS. Ata da $215^{\text {a }}$ reunião ordinária, de $1^{\circ}$ de fevereiro de 1967. Livro Ata 03, p. 122-123).

Tendo em vista situações dessa natureza, tanto nos serviços de saúde pública como nos de assistência médica previdenciária, houve outros momentos de reação coletiva e até mobilização política da categoria médica diante da socialização da medicina, envolvendo profissionais são-carlenses e de outras localidades paulistas, além de colegas de diferentes partes do país. Ainda em 1953, os médicos sãocarlenses reuniram-se extraordinariamente na SMSC para deliberar sobre a "Jornada de Protesto", que antes havia sido proposta no âmbito da Associação Médica Brasileira (AMB) à qual a SMSC havia se filiado através da APM. Diante do exposto, os sócios da SMSC decidiram participar do movimento, embora fossem desfavoráveis à possibilidade de paralisação dos serviços médicos. Eles ainda resolveram que seu representante propusesse um protesto a ser realizado por colegas em todos os municípios brasileiros, de modo que os médicos de cada localidade procurassem as prefeituras e seus mandatários, a fim de que estes representassem os médicos de seus municípios junto ao governo federal, pois este não estava atendendo aos anseios da categoria (SOCIEDADE MÉDICA DE SÃO CARLOS. Ata da reunião extraordinária da Sociedade Médica de São Carlos, de 25 de março de 1953. Livro Ata 01, p. 69).

Por outro lado, quanto aos atendimentos que passou a realizar no Serviço de Assistência Médica Domiciliar e de Urgência (SAMDU), ligado aos institutos previdenciários federais, o Médico 01 também enfatiza significativas diferenças 
da medicina socializada diante da modalidade de trabalho pré-existente (a prática liberal), especialmente no que se refere à relação médico-paciente e seu impacto sobre a autonomia médica. Dessa maneira, ele afirma:

Infelizmente, mudou muito. (...) Eu tinha um paciente que era do IAPFESP [Instituto de Aposentadoria e Pensões dos Ferroviários do Estado de São Paulo]. (...) Muito educado, fino, me chamava em casa com frequência. Eu ia, e ele estava me esperando no portão da frente. Abria pra eu entrar. Eu entrava, ele me acompanhava. Depois da consulta vinha aquela célebre bacia para eu lavar a mão. Assim foi... Um dia X qualquer... Eu era chefe do SAMDU. Ligou em casa para fazer um chamado. Minha esposa explicou para ele que o médico do SAMDU tinha faltado, e eu fui substituir (...). Ele foi e ligou para o SAMDU. E chamou um médico. Ele não sabia que eu era quem estava realmente de plantão. Não foi citado nome. E eu fui atender. Quando eu cheguei na casa dele, ele não estava na frente me esperando. Ele estava lá dentro na porta. Quando eu [coloquei] (...) a mão no portão, veio um cachorro latindo. Eu afastei. E ele continuou lá. Toda aquela gentileza que ele tinha com o médico particular, não teve com o médico público. $\mathrm{Eu}$ voltei. Aí ele veio para frente e falou: 'Onde é que o senhor vai?'... 'Vou-me embora'... 'Mas eu chamei o SAMDU'... 'O senhor não chamou o SAMDU. O senhor pôs o cachorro para atender. E eu não vou atender'. E ele falou: 'O senhor vai ter o desprazer de chegar lá e ter uma reclamação'. Eu falei: 'Eu estou aguardando'. E fui embora. Depois de uma hora ele apareceu lá. E falou com o moço da frente: 'Quero falar com o chefe do SAMDU'. (...) Quando ele me viu, ele quase desmaiou. E era uma pessoa educada, uma pessoa fina. Ao tratar com a medicina socializada, ele demonstrou o que ele esperava daquilo. E não havia nenhum atendimento ruim no SAMDU. Era um atendimento menos humano, como todo serviço público é, né? Agora, eu nunca aceitei bem que o médico aceitasse a situação que ele ficou no serviço público. Geralmente mantido, assim, sob um guidão de não-médicos. Isso aí era inaceitável. Mas foi o que aconteceu. O médico antes do serviço público... É lógico, você tem em toda profissão, modos diferentes de ser, de atender, né? Os nossos médicos eram muito carinhosos, de modo geral. E eram bairristas. Os pacientes também eram bairristas. Quem era daquele médico, era daquele, não trocava (...). Era uma medicina realmente diferente. A gente entendia, na escola, que era aquela medicina, que hoje, até hoje, todos querem, mas que não vai ter nunca mais. (...) Depois da socialização, foi o paciente é que foi complicando a coisa. Ele começou a atender mal o médico. E o médico reagiu. Reagiu mal também. (Entrevista com o Médico 01, profissional de São Carlos, entre 80-85 anos de idade). 
No entanto, os médicos perceberam certas vantagens antes inexistentes para a categoria. O próprio Médico 01 lembra que o atendimento em serviços socializados era, no início, realizado sem maiores dificuldades ou atrasos. Além de o médico receber um valor razoável pelo vínculo empregatício, ele ainda obtinha outros valores relativos às chamadas segunda e terceira tarefas - ou seja, aqueles valores recebidos quando, além do atendimento inicial, havia algum procedimento extra que o caso demandava, tais como cirurgias. Ao se multiplicarem os serviços sanitários estaduais e de assistência médica previdenciária (estadual e federal), foise permitido que se estendessem também o atendimento médico e de saúde a outros grupos sociais não localizados entre os segmentos médios e de elite, de modo que o mercado médico local encontrou, com o tempo, condições para o seu crescimento, na medida em que a própria população também aumentou com o desenvolvimento urbano-industrial do município. Tal crescimento do mercado local foi sustentado pelo aumento de grupos populares e de classes médias, os quais, com frequência, vieram a ser atendidos nos serviços médicos estatais.

Essa situação foi motivada pelos avanços nas condições sociais, econômicas e demográficas são-carlenses com seu desenvolvimento, a partir dos anos 1930 e 1940. Tais melhorias permitiram não apenas o crescimento do contingente populacional em geral e de pacientes demandantes de serviços de saúde, mas a multiplicação de profissionais, em especial desde o final dos anos 1960 (Entrevista com Moradora 01, professora de biologia, entre 50 e 55 anos de idade; Entrevista com Moradora 02, professora aposentada, entre 60 e 65 anos de idade), o que pode ser também notado ao se observar a frequência às reuniões da SMSC, pois, embora nem sempre contando com grande número de participantes, ainda assim, em ocasiões mais importantes, estas receberam considerável quantitativo médico (SOCIEDADE MÉDICA DE SÃO CARLOS. Ata da reunião extraordinária da SMSC para eleição da diretoria da APM para o biênio de 1957-1958, de 28 de novembro de 1956. Livro Ata 02, p. 39-40).

Contudo, em regiões interioranas como a de São Carlos-SP, mesmo com a maior abertura em termos de crescimento para o mercado médico em razão de avanços posteriores no desenvolvimento local, por muitos anos houve certa carência de médicos, não sendo fácil ou frequente chegada de novos pares de profissão. Durante anos dispensou-se a contratação de médicos nos serviços estatais por meio de concursos públicos, ao mesmo tempo em que não apenas certas especialidades permaneceram raras como, às vezes, quando efetivamente existentes no município, eram constituídas por apenas um único profissional, o qual por diversos anos acabava trabalhando isoladamente.

Por sua vez, o Médico 02 destaca que boa parte dos novos profissionais que começaram suas carreiras em São Carlos-SP a partir de 1945 e, pelo menos, até os anos 1960 e 1970 eram filhos de famílias radicadas no município, tendo, 
eles mesmos, nascido no município (Entrevista com o Médico 02, profissional de São Carlos, entre 60-65 anos de idade). Em geral, tais profissionais saíram de São CarlosSP apenas para estudar medicina, não somente, mas especialmente no Rio de Janeiro-RJ, retornando depois de formados, a fim de se estabelecerem em São Carlos-SP ${ }^{3}$. Contudo, apesar de encontrar, por vezes, alguma abertura em relação ao mercado médico local em razão desses contatos anteriories, o novo profissional teria de conquistar sua clientela e, neste caso, a organização dos novos serviços médicos estatais costumava contribuir na inserção de profissionais recém-chegados. Com o SAMDU, por exemplo, que foi criado para prestar assistência médica aos trabalhadores urbanos inseridos nos IAP's, o Médico 01 lembra que, em razão de o profissional fazer a maior parte dos atendimentos nos domicílios dos pacientes, o médico:

(...) ficava conhecendo o paciente. O paciente ficava conhecido do médico novo, porque o médico velho, de fama, não ia para o SAMDU. (...) E como era o processo de se mostrar na cidade? Através do SAMDU. (...) Naquele tempo, você precisava ser conhecido. Precisavam falar bem de você, se não você não entrava na cidade. O SAMDU fez isso para nós. Foi bom. (...) Tinha muita reclamação também, via jornal. Politicagem sempre existiu. Algumas com real valor, né? Outras sem (...). Mas o SAMDU mais ajudou que atrapalhou. (...) a gente ia ver o paciente do SAMDU em casa. Se era apendecite aguda, por exemplo, explicava para ele que ele ia ter custo. Naquele tempo não tinha INPS. (...) Então ia para o hospital. Chegando lá, ele ia com o seu médico. Mas foi você quem acompanhou. Se não tivesse ninguem, ele poderia escolher você para operar, e você começava a aparecer. (Entrevista com o Médico 01, profissional de São Carlos, entre 80-85 anos de idade).

Comentando sobre a mesma questão, mas no posterior contexto de unificação dos serviços previdenciários junto ao sistema INPS/INAMPS, o Médico 03 destaca que:

(...) então você tinha médicos credenciados através de entidades que prestavam serviço para o chamado INAMPS: Santa Casa, a própria Casa de Saúde (nos seus primórdios) [ambas de São Carlos, sendo a primeira criada em 1892 e a última nos anos 1960], atendia, tinha convênio com o INAMPS, entendeu? Então os médicos que faziam parte do corpo clínico e que se dispusessem a atender esses pacientes do sistema previdenciário eram muito bem-vindos, estava tudo aberto. Então, tinha-se garantia, desde logo, que havia uma remuneração, que ainda que não fosse grande, tá certo?, nunca foi e ainda não é. De qualquer forma, para quem

3 Dados confirmados em outras entrevistas realizadas para a pesquisa. 
estava começando, era um ponto de partida (...). (Entrevista com o Médico 03, profissional de São Carlos, entre 70-75 anos de idade).

Aliás, mesmo apresentando certos problemas, como também destaca o mesmo profissional, a assistência médica previdenciária, principalmente no seu início, tinha:

(...) um atendimento muito bom. Depois foi ficando difícil, porque os institutos de aposentadoria eram duros. O IAPB, dos bancários, tinha muito dinheiro. O IAPI também tinha. Alguns não tinham dinheiro. Então, quando juntaram todos os institutos, acabou diluindo o dinheiro. Não sobrou dinheiro para mais ninguém. Entendeu? Aí começaram a segurar as operações (...) Agora quando surgiu o INPS mesmo (...). Nós éramos empregados e recebíamos por mês. Atendíamos de manhã, por exemplo. (...) Não tinha que passar por lugar nenhum. Eu atendia o paciente com úlcera de estomago. Eu fazia a guia de encaminhamento. No dia seguinte, ele ia para o hospital, fazia todos os exames e operava. Não pedia permissão para ninguém. (...) A gente tinha um salário mensal. Todo doente atendido fora disso, operado, hospitalizado, você recebia como segunda tarefa. Pequenas cirurgias, que hoje se fica dois meses na fila, nós fazíamos no mesmo dia, como uma terceira tarefa. Então, o nosso salário ligado à medicina social era um salário muito bom. E a classe média continuava a procurar o médico particular. Isso mudou com a UNIMED. (Entrevista com o Médico 01, profissional de São Carlos, entre 80-85 anos de idade).

Dessa maneira, com a socialização da medicina em São Carlos-SP, e considerando os aspectos positivos e negativos às três dimensões da autonomia médica supramencionados, afora o trabalho no campo da saúde pública, cuja abrangência englobava os serviços preventivos e os cuidados no combate as epidemias e endemias, atingindo praticamente toda e qualquer pessoa que viesse a precisar de seus atendimentos, na área da assistência médica, com a emergência dos serviços previdenciários, além do tradicional atendimeto curativo a pacientes particulares e indigentes, que já se fazia pela prática médica liberal antes de o processo de socialização se intensificar, os médicos também passaram, desde a Era Vargas, a atender doentes através de serviços ligados tanto às iniciais caixas como aos posteriores institutos de aposentadoria e pensões, ou mesmo, depois da unificação dos institutos, junto ao INPS, ao INAMPS e ao FUNRURAL. Essa realidade afetou todo o sistema de atendimento médico que até o início da década de 1940 vinha se realizando no município. Com o tempo, os serviços médicos previdenciários produziram certos problemas de ordem financeira aos médicos locais, os quais, com frequência, mesmo com a ajuda da SMSC, tinham pouca margem de interferência para favorecer aos interesses da categoria. 
Como os dados das Atas da Sociedade Médica indicam, por diversas vezes, os médicos reclamavam de atrasos nos pagamentos que deveriam receber - tanto antes, com os diferentes IAP's, como depois, com o advento do INPS/INAMPS e do FUNRURAL. Impulsionada por seus associados, que procuravam algum amparo junto aos colegas e à própria organização da Sociedade Médica quando tais questões se agravavam, a direção da SMSC procurava agir no sentido da defesa de seus membros, mas geralmente sem maiores consequências. Houve diferentes circunstâncias em que a SMSC procurou reagir, realizar alguma ação em resposta ou, pelo menos, encaminhar reclamações por meio de ofícios aos diversos órgãos da previdência social, mas sem que fosse atendida em seus protestos (Entrevista com o Médico 04, profissional de São Carlos entre 80-85 anos de idade). A distância não apenas institucional, mas geográfica e até política, da direção superior desses institutos dificultava a atuação da entidade médica são-carlense na defesa da autonomia profissional da categoria.

Entretanto, mesmo com tal distância e dificuldade de influência sobre as autoridades públicas, particularmente as atuantes em órgãos federais, outras relações e contatos sociais e políticos mais informais se constituíam, quando havia esta possibilidade, e podiam atuar como recursos alternativos que auxiliavam os médicos são-carlenses na defesa de seus interesses - não propriamente aqueles que afetavam a coletividade médica, mas outros em específicas situações de determinados profissionais. A influência dos políticos era algo presente nos serviços previdenciários, o que interferia na autonomia profissional médica especialmente em sua dimensão política sendo que, às vezes, essa interferência atrapalhava o cotidiano de trabalho dos médicos. Por outro lado, em outras oportunidades, tal interferência poderia até ajudá-los. Foi o que aconteceu com o Médico 01, que conseguiu acesso junto ao presidente da República, João Goulart (PTB), o qual, através do deputado são-carlense Antonio Donato ${ }^{4}$, também do PTB, interferiu em sua recondução ao cargo de médico-chefe do SAMDU de São Carlos-SP, do qual ele havia sido afastado por razões político-partidárias.

Por outro lado, pode-se dizer que, desde o ponto de vista de sua autonomia profissional, outra era a realidade e outros eram os termos que frequentemente mediavam os vínculos dos médicos com serviços que, embora não estatais, ainda assim eram considerados pelos profissionais como serviços socializados, quais sejam: os serviços assistenciais do Serviço Social da Indústria (SESI), do Serviço Nacional de Aprendizado Industrial (SENAI) e do Serviço Social do Comércio

\footnotetext{
4 Foi contador e advogado. Começou na política elegendo-se vereador da Câmara Municipal de São Carlos pelo Partido Trabalhista Brasileira (PTB), entre 1948 a 1952, e também para as legislaturas de 1956-1960 e 1960-1964. Entre 1963 e 1967, foi deputado estadual, pelo PTB. Com o fim do pluripartidarismo, filiou-se à Aliança Renovadora Nacional - ARENA. Informações de acordo: http://al-sp. jusbrasil.com.br/noticias/1973732/morre-ex-deputado-antonio-donato, consultadas em 21/01/2016.
} 
(SESC) de São Carlos-SP. Os médicos desses órgãos eram empregados contratados e integravam serviços que eram tidos como de:

(...) atendimento assim, de elite. Não o paciente, mas quem lidava com você era a elite. Elite do SESC, do SESI, do SENAI e a elite médica. Então o atendimento era muito bom. Porque o médico não tinha coragem de atender mal um paciente em função do patrão. Era uma coisa interessante. (...) Era um regime mais rígido. Tinha paciente para esse tempo todo. E o médico não tinha coragem de afrontar o patrão. Faziam parte do mesmo grupo, grupo social de elite. (Entrevista com o Médico 01, profissional de São Carlos, entre 80-85 anos de idade).

\section{Considerações finais}

Tendo em vista os aspectos concernentes à socialização da medicina, poderíamos retomar o posicionamento do Médico 01 - em alinhamento com outras entrevistas e dados pesquisados - segundo o qual, apesar de certos conflitos emergentes entre médicos e pacientes, a socialização teria sido positiva, já que o médico passou a atender a um público mais amplo, que não apenas de estratos sociais abastados. Ela teria sido favorável à especialização médica pelo maior tempo de trabalho dos profissionais em organizações de saúde e hospitais. No início, a medicina estatal também teria acertado no atendimento, pois não havia filas de pacientes, sendo que os médicos recebiam em dia.

Com a abertura oferecida pela socialização, ampliou-se as vagas para médicos, mas isso teria sido acompanhado de mais disputas e da influência política sobre a ocupação de cargos pelos médicos, o que prejudicou a categoria. Quando o INAMPS surgiu, os pagamentos, que já não atendiam a profissão, tornaram-se mais adequados e regulares; entretanto, isso durou pouco tempo. No anterior modelo das Caixas de Aposentadoria e Pensão, só recebia atendimento quem fazia parte de determinada caixa. Nos IAP's, passou-se a descontar um valor dos dividendos dos beneficiários, e esse dinheiro não ia para ele ou para o instituto, e começaram, segundo os médicos, os descaminhos de recursos. Com a unificação dos IAP's, o governo federal teria assumido ainda mais controle sobre o destino das verbas e aumentado os problemas existentes no sistema, o qual, ao final dos anos 1970, já se encontrava em grave crise.

A partir desta avaliação de caráter geral e dos demais dados analisados, os médicos são-carlenses, tal como colegas de outras cidades paulistas e do resto do pais, tiveram de enfrentar a nova realidade da interiorização da medicina socializada, com seus problemas e restrições ao profissionalismo médico. No entanto, visto pelos próprios profissionais como um amplo e necessário processo, a expansão da 
medicina estatal teria trazido avanços na assistência à saúde, verificados não somente da perspectiva dos médicos, mas também do ponto de vista da população.

\title{
The SOCIALIZATION OF MEDICINE IN THE HINTERLAND OF São Paulo: the case of São Carlos (1889-1988)
}

\begin{abstract}
This paper focuses on the development of socialized medicine in the countryside between 1889 and 1988, as well as the economic and political development of the State of São Paulo. It investigates how the centralization of the Brazilian state created new medical services at the state level, and how this influenced the professional autonomy of medical personnel. The study centers on socialized medicine in São Carlos (SP), where these social factors had an impact during this timeframe, creating specific consequences on both the socialization of medicine and the professional autonomy of medical practices. From the point of view of medical autonomy, socialization produced positive as well as negative effects. The reality of São Carlos is a good example of how the socialization of medicine took effect in São Paulo, and also, more generally, in the wider Brazilian countryside. The research used bibliographical research as well as the minutes of the Sociedade Médica de São Carlos and 15 interviews with physicians and local citizens based on oral history.
\end{abstract}

KEYWORDS: Internalization. Socialization of medicine. Development. Professional autonomy of medicine. São Carlos.

\section{LA SOCIALIZACIÓN DE LA MEDICINA EN EL INTERIOR paulista: el caso de São Carlos (1889-1988)}

RESUMEN: El artículo se centra en la interiorización de la medicina socializada y el desarrollo económico y político del interior paulista entre 1889 y 1988. Considera, en particular, el impacto de la centralización política del Estado sobre el desarrollo brasileño, la consiguiente ampliación de la medicina estatal y sus efectos sobre la autonomía profesional médica. El análisis examina el especial caso de socialización de la medicina en São Carlos (SP), donde estos factores sociales se mostraron influyentes en el periodo, concediendo especificidades sobre la autonomía médica. Desde la perspectiva de esta autonomía, la socialización produjo efectos positivos y negativos. La realidad são-carlense expresa un caso representativo de como se dió la socialización de la medicina en el interior paulista y, en parte, en 
el interior del país en general. La investigación inspeccionó fuentes bibliográficas, Actas de la Sociedad Médica de São Carlos y 15 entrevistas basadas en fuentes orales con médicos y ciudadanos são-carlenses.

PALABRAS CLAVE: Interiorización. Socialización de la medicina. Desarrollo. Autonomía profesional de la medicina. São Carlos.

\section{REFERÊNCIAS}

ALMEIDA, Fabio de Oliveira. Coesão e interesses da medicina paulista diante do populismo adhemarista: contradições e ambivalências. In: Sociedade e Cultura: Revista de Pesquisa e Debates em Ciências Sociais. Goiânia, vol. 14, nº 01, pp.131-139, 2011.

. Profissionalismo médico paulista e reforma na saúde adhemarista. São Carlos, EdUFSCar, 2013.

. A socialização da medicina na era do adhemarismo. In: História, Ciências, Saúde - Manguinhos, Rio de Janeiro, vol. 21, n. ${ }^{\circ}$ 04, pp. 1379-1396, 2014.

. Ondas de interiorização do profissionalismo médico e o desenvolvimento em São Carlos. 2016, 373f. Tese (Doutorado em Sociologia) - Programa de Pós-Graduação em Sociologia, Universidade Federal de São Carlos, São Carlos, 2016.

BARBOSA, Maria Lígia de Oliveira. A sociologia das profissões: em torno da legitimidade de um objeto. In: Revista Brasileira de Informação Bibliográfica em Ciências Sociais - BIB. Rio de Janeiro, $\mathrm{n}^{\mathrm{o}} 36,2^{\circ}$ semestre de 1993, pp. 3-30.

. Para onde vai a classe média: um novo profissionalismo no Brasil? In: Tempo Social. São Paulo, 10, nº 01, pp. 129-142, 1998.

BENEVIDES, Maria Vitória. O governo Kubitschek: desenvolvimento econômico e estabilidade política. Rio de Janeiro, Paz e Terra, 1979.

BONELLI, Maria da Gloria. Estudos sobre as Profissões no Brasil. In: Sergio Miceli. (org.). O que ler na Ciência Social Brasileira. São Paulo, Editora Sumaré e ANPOCS, 1999. Volume 2, p. 285-328.

. Profissionalismo e política no mundo do Direito: as relações dos advogados, desembargadores, procuradores de justiça e delegados de polícia com o Estado. São Carlos, EdUFSCar e Editora Sumaré, 2002.

BONELLI, Maria da Glória; DONATONI, Silvana. O estudo sobre profissões nas ciências sociais brasileiras. In: Revista Brasileira de Informação Bibliográfica em Ciências Sociais BIB. Rio de Janeiro, n. 41, $1^{\circ}$ semestre de 1996, p. 109-142. 
BONELLI, Maria da Gloria; NUNES, Jordão Horta; MICK, Jacques. Ocupações e profissões na Sociedade Brasileira de Sociologia: balanço da produção (2003-2017). In: Revista Brasileira de Sociologia. Fortaleza, vol. 05, $\mathrm{n}^{\mathrm{o}}$ 11, set/dez, 2017, p. 18-28.

CASTRO SANTOS, Luiz Antonio de. Poder, ideologias e saúde no Brasil da Primeira República: ensaio de sociologia histórica. In: HOCHMAN, Gilberto; ARMUS, Diego (org.). Cuidar, controlar, curar: ensaios históricos sobre saúde e doença na América Latina e Caribe. Rio de Janeiro, Fiocruz, 2004, p. 249-293.

DONNANGELO, Maria Cecília Ferro. Medicina e sociedade: o médico e seu mercado de trabalho. São Paulo, Editora Pioneira, 1975.

DRAIBE, Sônia. Rumos e metamorfoses. São Paulo, Editora Paz e Terra, 1985.

FREIDSON, Eliot. Profissão médica: um estudo de sociologia do conhecimento aplicado. São Paulo, Editora UNESP; Porto Alegre, Sindicato dos Médicos, 2009.

. Para uma análise comparada das profissões: a institucionalização do discurso e do conhecimento formais. In: Revista Brasileira de Ciências Sociais. São Paulo, nº. 31, junho, 1996.

HOCHMAN, Gilberto. A era do saneamento: as bases da política de saúde pública no Brasil. São Paulo, Editora Hucitec/ANPOCS, 1998.

KERBAUY, Maria Teresa Miceli. A morte dos coronéis: política interiorana e poder local. Araraquara, FCL/Laboratório Editorial/UNESP; São Paulo, Cultura Acadêmica Editora, 2000 .

LIMA, Renata Priore. Limites da legislação e o (des)controle da expansão urbana. São Carlos, EdUFSCar, 2008.

MEIHY, José Carlos Sebe B.; RIBEIRO, Suzana L. Salgado. Guia prático de história oral. São Paulo, Contexto, 2011.

RODRIGUES, Maria de Lurdes. Sociologia das profissões. Oeiras, Celta, 2001.

SANTOS, André Felipe Pereira Reid dos. Principais abordagens sociológicas para a análise das profissões. In: Revista Brasileira de Informação Bibliográfica em Ciências Sociais BIB, São Paulo, n. 71, $1^{\circ}$ semestre de 2011, pp. 25-43.

SOCIEDADE MÉDICA DE SÃO CARLOS, de 09 de agosto de 1950. Livro Ata 01, p. 24-25.

SOCIEDADE MÉDICA DE SÃO CARLOS. Ata da $27^{\mathrm{a}}$ reunião ordinária, de 06 de dezembro de 1950, p. 29.

SOCIEDADE MÉDICA DE SÃO CARLOS. Ata da reunião extraordinária da Sociedade Médica de São Carlos, de 25 de março de 1953. Livro Ata 01, p. 69. 
SOCIEDADE MÉDICA DE SÃO CARLOS. Ata da $92^{\mathrm{a}}$ reunião ordinária, de 02 de maio de 1956. Livro Ata 01, p. 23-25.

SOCIEDADE MÉDICA DE SÃO CARLOS. Ata da reunião extraordinária da SMSC para eleição da diretoria da APM para o biênio de 1957-1958, de 28 de novembro de 1956. Livro Ata 02 , p. 39-40

SOCIEDADE MÉDICA DE SÃO CARLOS. Ata da $103^{\mathrm{a}}$ reunião ordinária, de 03 de abril de 1957. Livro Ata 01, p. 45-46.

SOCIEDADE MÉDICA DE SÃO CARLOS. Ata da $106^{\mathrm{a}}$ reunião ordinária, de 05 de agosto de 1957. Livro Ata 01, p. 50-51.

SOCIEDADE MÉDICA DE SÃO CARLOS. Ata da $196^{\mathrm{a}}$ reunião ordinária, de 03 de fevereiro de 1965. Livro Ata 03, p. 96-97.

SOCIEDADE MÉDICA DE SÃO CARLOS. Ata da $208^{\mathrm{a}}$ reunião ordinária, de 06 de abril de 1966. Livro Ata 03, p. 115-116.

SOCIEDADE MÉDICA DE SÃO CARLOS. Ata da $215^{\mathrm{a}}$ reunião ordinária, de $1^{\circ} \mathrm{de}$ fevereiro de 1967. Livro Ata 03, p. 122-123.

TRUZZI, Oswaldo. Café e Indústria: São Carlos: 1850-1950. São Carlos, EdUFSCar, 2007.

WEBER, Max. A 'objetividade' do conhecimento nas Ciências Sociais. In: COHN, Gabriel (org.). Max Weber: sociologia. São Paulo, Editora Ática, p. 79-127, 1983.

Recebido em 03/03/2017.

Aprovado em 14/10/2018. 